\title{
Contribuições do modelo de Análise Proposicional de Conceitos (APC) para a elaboração e validação de uma sequência didática com abordagem histórico-filosófica
}

\section{Contributions of the Propositional Analysis of Concepts (PAC) model for the elaboration and validation of a didactic sequence with a historical-philosophical approach}

\author{
Helenara Regina Sampaio Figueiredo \\ helenara.sampaio@yahoo.com.br
}

Irinéa de Lourdes Batista

irinea@uel.br

\begin{abstract}
Resumo
Este artigo apresenta os resultados de uma investigação acerca da construção e aplicação de uma sequência didática de trigonometria, validados por meio de um instrumento da Aprendizagem Significativa, denominado Análise Proposicional de Conceitos (APC). Dessa forma, este estudo intenta contribuir para uma abordagem histórico-filosófica e para a validação da aprendizagem de trigonometria no Ensino Médio. A sequência didática fundamenta-se na Metodologia de pesquisa denominada Engenharia Didática, aplicada aos alunos do Ensino Médio de uma escola pública de Londrina - PR. Foi possível chegar a conclusão de que a abordagem construída mostrou-se eficaz para aprendizagem de trigonometria, possibilitando a manifestação dos valores cognitivos da matemática na sequência didática e sua incorporação ao conhecimento do aluno.
\end{abstract}

Palavras-chave: Aprendizagem significativa; Análise Proposicional de Conceitos; Valores cognitivos; Trigonometria.

\begin{abstract}
This paper aims to show the results of an investigation about the construction and application of a didactic sequence of trigonometry, validated through a Significant Learning instrument called Propositional Analysis of Concepts (PAC). Thus, this study aims to contribute to a historical-philosophical approach and the validation of trigonometry learning in High School. The didactic sequence is based on the research methodology called Didactic Engineering, applied to the high school students of a public school in the city of Londrina - Paraná state. It was possible to conclude that the constructed approach proved to be effective for learning trigonometry, enabling the manifestation of mathematics cognitive values in the didactic sequence and its incorporation into the student's knowledge.
\end{abstract}

Keywords: Significant learning; Propositional Analysis of Concepts; Cognitive values; Trigonometry.

\section{Introdução}

Em nossa pesquisa de Mestrado em Ensino de Ciências e Educação Matemática, construímos uma abordagem histórico-filosófica de trigonometria para o Ensino Médio. Nela, elaboramos uma reconstrução histórica capaz de contemplar a discussão dos valores cognitivos constitutivos da ciência aplicados a Educação Matemática.

A História da Matemática permitiu conhecer os problemas que originaram a construção do conhecimento matemático e como esses se articularam com conteúdos de outras disciplinas. Nesse sentido, discutimos as contribuições da História da Matemática e da Filosofia da Ciência para o ensino e aprendizagem desse conteúdo matemático.

Recorremos à Filosofia da Ciência, a respeito das discussões dos valores cognitivos constitutivos da ciência que, em nossa discussão, puderam ser atribuídos à Matemática. Consideramos que esses valores precisam ser explicitados para justificarem a importância dos conceitos 
trigonométricos na Educação Básica. Diante disso, a pergunta norteadora delineada para orientar neste processo investigativo foi "Quais as adequações e transformações necessárias ao ensino de Trigonometria, a partir de uma abordagem histórico-filosófica? Para tanto, julgamos pertinente elaborar uma questão específica para auxiliar a responder à questão principal: A nossa sequência didática, construída com tal abordagem, possibilitará que os alunos participem ativamente da aquisição do conceito de Ciclo Trigonométrico?

Assim, analisamos, por meio de uma reconstrução histórica, a manifestação destes valores em diferentes épocas e contextos e observamos um potencial pedagógico e problematizador de conteúdos escolares, justificando adotá-los no contexto escolar. O objetivo deste item consiste numa discussão na Educação Matemática em uma perspectiva que envolva valores cognitivos dotados de critérios para que uma teorização científica se torne racionalmente aceitável. Dessa forma, buscamos situar tal discussão na Filosofia da Ciência, partindo de Hugh Lacey (1998) como referencial teórico, pois ele aborda a racionalidade científica em termos de valores cognitivos e sociais. Ao expor sua obra Valores e Atividade Cientifica, reporta-se ao processo epistemológico de seleção de teorias em termos de compromisso com um conjunto de valores cognitivos.

O objetivo de nossa pesquisa foi investigar a construção de uma abordagem históricofilosófica para o ensino do ciclo trigonométrico no Ensino Médio, na qual visamos elaborar uma reconstrução histórico-epistemológica e teórico-conceitual do assunto ciclo trigonométrico, investigando assim as relações, adaptações e transposições pertinentes à Engenharia Didática, aplicáveis às abordagens histórico-filosóficas com vistas à aprendizagem de trigonometria no Ensino Médio.

Segundo Lacey (1998, p. 61), vários autores afirmam que os valores cognitivos constitutivos da ciência são critérios a serem satisfeitos por uma boa teoria científica, enfatizando que tais valores são diferentes de valores morais, sociais, entre outros.

Lacey (1998, p. 62-63) apresenta uma lista de valores cognitivos que desempenharam algum papel na escolha de teorias, pelo menos em alguns momentos da ciência, elaborada a partir de vários referenciais, podendo ser completada, ainda, com outros valores cognitivos. A seguir, apresentamos os valores cognitivos citados por Lacey:

- Adequação empírica: ser empiricamente testável, ter correspondência com o real, ter primazia dos dados experimentais e quantitativos, exatidão, precisão dos dados;

- Consistência: tem consistência no interior da própria teoria e com outras aceitas;

- Simplicidade: tem harmonia, elegância, clareza conceitual, eficiência no seu uso, coerência;

- Fecundidade: origina novas questões, desencadeia novos programas de pesquisa, tem capacidade de predição, ocasiona a descoberta de novos fenômenos, soluciona quebra-cabeças;

- Poder explicativo: fornece explicações para os fenômenos numa ampla extensão de domínios, tem profundidade, possibilita a construção de uma narrativa que ofereça explicações;

- Verdade, certeza: verdade acerca dos princípios fundamentais, necessidade;

- Generalização: capacidade de ser generalizada, formalizada.

Para a elaboração da lista de valores cognitivos, Lacey (1998) aponta então a primeira tarefa:

"que é interpretativa e consiste na reconstrução racional de episódios-chave de escolha de teorias e de controvérsias teóricas, a fim de discernir os critérios que podem ser razoavelmente apontados e confrontados com as reflexões críticas dos cientistas ativos" (LACEY, 1998, p. 66).

Usamos, em nossa pesquisa, a lista dos valores cognitivos proposta por vários autores e citada no livro de Lacey (1998, p. 61-66) que, segundo o autor, não está fechada, pois os critérios para uma boa teoria e suas interpretações podem variar. A discussão dos valores cognitivos está voltada 
para nossa reconstrução histórica da trigonometria, identificando, por meio dela, que valores cognitivos desempenharam seu papel nessa história.

Para Batista (2005, p. 736),

"a abordagem histórico-filosófica funciona como um fio condutor dos raciocínios, como um elemento na estrutura didática que favorece a cognoscibilidade dos conteúdos, que justifica racionalmente sua coordenação didática, estabelecendo-se no próprio corpo integrado das estruturas de ensino e, como pretendemos, de aprendizagem."

Recorremos à história com finalidades diretamente relacionadas com as práticas em sala de aula. Uma delas é criar problemas que possam ser debatidos entre professor e aluno. Tais problemas não são os encontrados na História da Matemática, mas possibilitam debater alguns aspectos epistemológicos presentes na construção histórica do conhecimento trigonométrico e criar oportunidades de investigação para a Educação Matemática.

Para justificar a participação da história no processo de ensino-aprendizagem da Matemática, Miguel (1993, p. 6) apresenta uma lista de argumentos reforçadores das potencialidades pedagógicas da história. Nessa lista, ele destaca uma função que ele denomina "História-Axiologia", considerando a História da Matemática como um instrumento promotor de atitudes e valores, na concepção dos fins da educação Matemática e dos valores por ela promovidos (MIGUEL, 1993, p. 22). Também salienta que "para serem pedagogicamente úteis, é necessário que histórias da Matemática sejam escritas sob o ponto de vista do educador matemático" (MIGUEL, 1993, p. 109).

O valor cognitivo consistência é analisado quando a trigonometria mostrou sua consistência com outras teorias, como os estudos dos pêndulos na Física, e se desenvolve dentro da própria Matemática com o estudo dos logaritmos. A trigonometria deixou de ter o caráter geométrico e passou a ter maior desenvolvimento algébrico, tornando-se generalizável. Novas descobertas de fenômenos e capacidade de previsões mostraram o valor cognitivo fecundidade. A trigonometria tornou possível a explicação do Sistema Solar, com cálculos cada vez mais precisos não só para a Matemática, como também para outras ciências.

Embora reconheçamos a existência de outros valores envolvidos no processo de construção desse conhecimento matemático, como os valores sociais, institucionais, entre outros, tomamos como enfoque neste trabalho a apresentação de um levantamento de hipóteses iniciais de valores cognitivos, questionando-nos sobre quais são os possíveis valores cognitivos presentes na História da Matemática que favoreceram a escolha do conteúdo de Trigonometria Plana na Educação Básica.

Para a elaboração da sequência de ensino, adotamos uma metodologia denominada Engenharia Didática, tendo como hipótese a adequação de sua estrutura aos nossos objetivos de construção de abordagem, a fim de contemplar a dimensão teórica da História da Matemática a partir dos referenciais e conduzir sua experimentação para investigação na nossa prática educativa. Tal justificativa vem ao encontro dos mesmos propósitos da Engenharia Didática (Pais, 2002, p. 99), que é "vista como metodologia de pesquisa, caracteriza-se por um esquema experimental baseado em realizações didáticas na sala de aula, isto é, na concepção, na realização, na observação e a análise de sequências de ensino" (ARTIGUE, 1996, p. 196).

Segundo Artigue (1996, p. 196), podemos distinguir quatro fases no processo da Metodologia da Engenharia Didática:

$\mathbf{1}^{\mathrm{a}}$ fase: Análises preliminares;

As análises preliminares para a concepção da engenharia são feitas por meio de considerações do quadro teórico didático geral e sobre o assunto em questão.

$2^{\text {a }}$ fase: Análise a priori das situações propostas na sequência didática;

$\mathrm{Na}$ fase da concepção e da análise a priori, o pesquisador, orientado pelas análises 
preliminares, delimita certo número de variáveis pertinentes ao sistema sobre as quais o ensino pode atuar, as quais são chamadas de variáveis de comando. Supõe-se serem variáveis pertinentes para o problema estudado.

\section{$3^{\text {a }}$ fase: A experimentação;}

A fase da experimentação se apóia no conjunto de dados recolhidos na realização da engenharia, iniciando no momento em que o pesquisador e alunos sujeitos da investigação entram em contato.

Os dados recolhidos decorrem dos seguintes meios:

- o registro das observações realizadas durante a experimentação, em diversos momentos do ensino;

- produção dos alunos em classe ou externas;

- a aplicação dos instrumentos de pesquisa, por meio de questionários, testes individuais ou em pequenos grupos.

\section{$4^{\text {a }}$ fase: Análise a posteriori e da avaliação:}

Nesta fase, realiza-se o tratamento dos dados que constam da seleção dos dados pertinentes à análise a posteriori. É no confronto das duas análises, a priori e a posteriori, que se baseia a validação das hipóteses levantadas na pesquisa.

A Engenharia Didática caracteriza-se pelo registro dos estudos feitos sobre o caso em questão e pela sua forma de validação dos resultados. Essa validação da pesquisa é feita, sobretudo, internamente, pois ela se baseia na confrontação entre a análise a priori, que por sua vez, se apóia no quadro teórico, e a análise a posteriori. Na Engenharia Didática, a validação é interna, enquanto que a baseada nos métodos estatísticos é externa, ou seja, utilizam métodos comparativos para validar seus resultados.

Analisamos os resultados empíricos da investigação tomando dos referenciais da Aprendizagem Significativa um instrumento denominado Análise Proposicional de Conceitos para fazer o levantamento do conhecimento prévios dos alunos a respeito dos conceitos trigonométricos e, principalmente, para resolver um problema levantado pela Metodologia da Engenharia Didática sobre a validação da aprendizagem por meio de sequências didáticas.

Para Pais (2002, p. 98), é possível com a utilização de uma Engenharia Didática reforçar a confiabilidade da pesquisa, em especial, por estar vinculada com a realidade da sala de aula. Em nossa investigação para análise dos resultados da aplicação da sequência, foi utilizado o instrumento de Análise Proposicional de Conceitos, no qual um questionário foi respondido num primeiro momento de contato com os alunos e no momento final da aplicação. Por meio do primeiro APC, foi possível elaborar uma sequência didática que fosse ao encontro das principais dificuldades dos alunos, a partir de um levantamento do conhecimento prévio do aluno a respeito do conteúdo básico de Trigonometria, que é um conteúdo que faz parte do currículo da última série do Ensino Fundamental, e também de questões referentes aos valores cognitivos incorporados ao conhecimento do aluno. Com a aplicação do APC a posteriori, objetivamos analisar se houve mudanças nas respostas do público alvo.

\section{A Análise Proposicional de Conceitos (APC)}

Artigue (1996) aponta que, na maior parte das pesquisas relativas à Engenharia Didática, os autores não se envolvem num processo de validação verdadeiro, pois o confronto das duas análises $a$ priori e a posteriori exibe distorções. Assim, as hipóteses levantadas no trabalho não garantem que, a longo prazo, de fato, torne-se validada a aprendizagem.

Como Pais (2002) ressalta que a validação é um dos problemas clássicos da Engenharia Didática, buscamos na Teoria da Aprendizagem Significativa a sistemática de avaliação "Análise Proposicional de Conceitos" (APC) para uma validação dos resultados de nossa pesquisa.

Novak e Gowin (1999) afirmam que ela pode ser utilizada na avaliação de um instrumento 
de coleta de dados (como, por exemplo, o questionário) visando o enriquecimento da investigação. Esse método "se baseia na noção psicológica de que o significado que um dado conceito tem para um estudante é manifestado através do conjunto de pré-proposições incorporando o conceito que o estudante elabora" (NOVAK E GOWIN, 1999, p.156).

Esse método é aplicado antes e depois da instrução e se caracteriza por determinar o conjunto de proposições formuladas pelo professor no âmbito, por exemplo, de um questionário, de acordo com as questões elaboradas por ele próprio acerca do resultado que se almeja na pesquisa. Em seguida, identificam-se os enunciados pré-proposicionais formulados pelo aluno durante a transcrição do questionário. A partir daí, elabora-se uma tabela que mostre, de um lado (esquerdo), as proposições dadas pelos alunos antes da instrução e, do outro (direito), as proposições respondidas pelos alunos às mesmas perguntas depois da instrução. No centro da tabela, localizam-se as principais proposições que são apresentadas na instrução, ou seja, as perguntas ou proposições elaboradas pelo professor ou pesquisador para a realização da entrevista.

Para Novak e Gowin (1999), esse método é vantajoso, pois aos alunos não se impõe nenhum tipo de estrutura pré-determinada que interfira na construção de suas proposições. Essa técnica permite também aos professores valerem-se dos conhecimentos prévios apresentados pelos alunos como ponto de partida para o ensino de conteúdos que queiram trabalhar.

Ao aplicarmos a análise proposicional de conceitos antes e após a instrução, foi possível elaborarmos uma tabela na qual mostramos:

- as proposições dadas por um estudante antes da instrução;

- as principais proposições que exemplificam a instrução;

- as proposições com que responde um estudante às mesmas perguntas, depois da

instrução.

\section{Descrição dos resultados da aplicação}

Nesta análise fundamentada nos APCs, compreendendo questões realizadas antes da aplicação e no final da aplicação da sequência didática, pudemos estudar as respostas dos 23 alunos, para fazer a validação da aprendizagem.

Vários questionamentos foram feitos diante da necessidade de clarificar dúvidas que pudessem surgir e que nos auxiliassem nas análises sobre os valores cognitivos da matemática.

A questão 1, "Você considera a matemática importante?" foi analisada em ambos os APCs. Já a questão 2, "Dos conteúdos matemáticos já estudados até hoje, qual você achou mais interessante aprender?", só foi feita no APC 1, com o objetivo de perceber se algum aluno citaria que a trigonometria da última série foi um conteúdo que ele achou importante aprender, mas nenhum aluno a citou.

A questão 3 foi composta de várias alternativas em que estavam implícitos os valores cognitivos da matemática:

3) Marque $x$ nas afirmativas que você considera verdadeiras em relação à Matemática:

a ( ) Contribui para resolver problemas tanto na matemática como em outras disciplinas.

b ( ) Busca cada vez mais resultados exatos.

c ( ) Aplica-se a matemática para resolver problemas reais do dia-a-dia.

d ( ) A matemática quase não faz sentido para produzir novas descobertas.

e ( ) As fórmulas matemáticas tornam os cálculos mais simples.

f ( ) Os conteúdos que hoje estudamos podem ser úteis no futuro.

g ( ) Tudo seria mais fácil se não existisse a matemática.

h ( ) Mesmo usando cálculos matemáticos, a inexatidão é constante.

i ( ) A representação gráfica ajuda o aluno a compreender melhor os conceitos matemáticos.

$\mathrm{Na}$ questão 4 e 5, queríamos fazer um levantamento dos conhecimentos prévios, questionando o que o aluno sabia de trigonometria, que itens ele relacionava com o mesmo conteúdo. 
No APC 2, tais questões não foram, portanto, analisadas.

4) $\mathrm{O}$ assunto trigonometria faz parte dos conteúdos da $8^{\mathrm{a}}$ série. Você estudou trigonometria nessa série? Quais foram os principais tópicos estudados?

5) Quando você pensa na trigonometria que termos têm a ver com esse conteúdo:

$$
\begin{aligned}
& \text { ( ) seno } \\
& \text { ( ) catetos } \\
& \text { ( ) perímetro } \\
& \text { ( ) graus }
\end{aligned}
$$

$$
\begin{aligned}
& \text { ( ) cubo } \\
& \text { ( ) adjacente } \\
& \text { ( ) razão } \\
& \text { ( ) potência }
\end{aligned}
$$

$$
\begin{aligned}
& \text { ( ) ângulos } \\
& \text { ( ) números complexos } \\
& \text { ( ) Teorema de Pitágoras } \\
& \text { ( ) divisor }
\end{aligned}
$$

Também foram colocados vários problemas para os alunos resolverem de trigonometria no triângulo-retângulo. A questão 6: "Os cálculos da trigonometria servem para resolver que tipo de problemas?" aparece nos dois APCs, para observarmos se houve mudanças nas respostas dos alunos de acordo com a aplicação da sequência didática.

Na questão 7, "Que motivos você pensa que levaram os matemáticos da Antiguidade a estudar a trigonometria?", nossa intenção foi ver o que o aluno pensava a respeito da história da matemática. Ela foi aplicada nos dois APCs.

Na questão 8, "Você acha que é importante estudar a história da matemática para aprender melhor? Justifique.", queríamos saber se para o aluno é importante estudar história da matemática para aprender melhor os conteúdos. Fizemos a mesma pergunta no APC 2 para ver se havia mudança de opinião a esse respeito.

Seguem-se os quadros de respostas e as análises de quatro alunos, que foram enumerados para preservar seus nomes. Para este artigo, selecionamos, de forma aleatória, quatro alunos dentre os 23 participantes que cumpriram todas as atividades e responderam ao APC1 e APC2.

Quadro 1: Respostas do aluno

\begin{tabular}{|l|l|l|l|}
\hline \multicolumn{1}{|c|}{ Aluno 1 } & \multicolumn{1}{|c|}{ APC 1 } & \multicolumn{1}{c|}{ Valores cognitivos } & \multicolumn{1}{c|}{ APC 2 } \\
\hline Q. 1: & $\begin{array}{l}\text { Usamos no dia-a-dia para } \\
\text { muitas coisas. }\end{array}$ & Adequação empírica. & $\begin{array}{l}\text { Usamos diariamente, para pagar } \\
\text { contas, etc. }\end{array}$ \\
\hline Q. 3: & Alternativas 1, 3, 5, 6, 9. & Exatidão. & Alternativas 1, 2, 3, 5, 6, 9. \\
\hline Q. 6: & Cálculos de ângulos. & $\begin{array}{l}\text { Generalização, poder } \\
\text { explicativo. }\end{array}$ & $\begin{array}{l}\text { Cálculos astronômicos, medir tg, } \\
\text { sen, cos. }\end{array}$ \\
\hline Q. 7: & Para chegar a um cálculo. & Exatidão. & $\begin{array}{l}\text { Para determinar tamanhos que } \\
\text { não eram corretos. }\end{array}$ \\
\hline Q. 8: & Para saber de onde ela veio. & Poder explicativo & $\begin{array}{l}\text { Para saber de sua história e do } \\
\text { porque a matemática. }\end{array}$ \\
\hline
\end{tabular}

Fonte: Da pesquisa

$\mathrm{Na}$ q. 1, o aluno mantém a mesma opinião, deixando implícito o valor cognitivo da adequação empírica da matemática, sua correspondência com o real. Na q. 3, acrescentou o valor cognitivo exatidão. Na q. 6, o aluno respondeu que a trigonometria é usada para calcular ângulos, o que nos levou a preparar atividades enfatizando sempre os ângulos. No APC 2, exemplificou sua importância para cálculos astronômicos e, ao usar a simbologia, mostrou o valor cognitivo generalização. Continuou a considerar importante a história da matemática para aprender os conteúdos.

Quadro 2: Respostas do aluno

\begin{tabular}{|l|l|l|l|}
\hline \multicolumn{1}{|c|}{ Aluno 2 } & \multicolumn{1}{|c|}{ APC 1 } & \multicolumn{1}{c|}{ Valores cognitivos } & \multicolumn{1}{c|}{ APC 2 } \\
\hline Q. 1: & $\begin{array}{l}\text { Dependendo o que o } \\
\text { indivíduo quer ser, não é } \\
\text { importante. }\end{array}$ & $\begin{array}{l}\text { Poder explicativo. } \\
\text { tamanhos. }\end{array}$ \\
\hline Q. 3: & Alternativas 1, 5, 9. & Adequação empírica. & Alternativas 1, 3, 5, 9. \\
\hline Q. 6: & Em branco. & Poder explicativo. & $\begin{array}{l}\text { Problemas geométricos, distâncias, } \\
\text { altura. }\end{array}$ \\
\hline
\end{tabular}




\begin{tabular}{|l|l|l|l|}
\hline Q. 7: & Em branco. & Poder explicativo. & $\begin{array}{l}\text { Calcular as distâncias dos planetas e } \\
\text { das estrelas. }\end{array}$ \\
\hline Q. 8: & $\begin{array}{l}\text { Com a história ajuda a } \\
\text { lembrar melhor. }\end{array}$ & $\begin{array}{l}\text { Porque quando aprendemos de onde } \\
\text { surgiu e para que foi inventada, nós } \\
\text { assimilamos melhor o conteúdo. }\end{array}$ \\
\hline
\end{tabular}

Fonte: Da pesquisa

Na q. 1, o aluno respondeu que a matemática não é importante para todos, mas no APC 2, o aluno afirmou que é importante e que pode ser usada para cálculos. Analisamos que o aluno percebeu que todos podem utilizar a matemática para resolver problemas. Na q. 3, o aluno acrescentou no APC 2 o valor cognitivo adequação empírica, reafirmando que a matemática pode ser aplicada a problemas reais do dia-a-dia. Na q. 6, o aluno deixou em branco no APC 1 e, no APC 2, ao responder que a trigonometria é usada para descobrir ângulos, alturas, analisamos que o aluno compreendeu as atividades que calculavam altura de prédio. $\mathrm{O}$ valor poder explicativo foi alcançado. Na q. 7, o aluno deixou em branco, e no APC 2 deu-nos um exemplo correto com o conteúdo apresentado. Consideramos alcançado o valor cognitivo poder explicativo. Esta análise se deve as respostas da q. 8, pois o aluno respondeu que a história da matemática é necessária para obter mais conhecimento, aprender melhor o conteúdo. Consideramos que na história da matemática o valor cognitivo poder explicativo foi evidenciado.

Quadro 3: Respostas do aluno

\begin{tabular}{|l|l|l|l|}
\hline \multicolumn{1}{|c|}{ Aluno 3 } & \multicolumn{1}{|c|}{ APC 1 } & \multicolumn{1}{c|}{ Valores cognitivos } & \multicolumn{1}{c|}{ APC 2 } \\
\hline Q. 1: & É necessária no dia-a-dia. & Adequação empírica. & É importante no dia-a-dia. \\
\hline Q. 3: & $\begin{array}{l}\text { Alternativas 1, 2, 3, 5, 6, } \\
8 .\end{array}$ & Generalização. & Alternativas 1, 2, 3, 5, 6, 8, 9. \\
\hline Q. 6: & Não sei. & Poder explicativo. & $\begin{array}{l}\text { Problemas relacionados } \\
\text { medidas. }\end{array}$ \\
\hline Q. 7: & Não sei. & Simplicidade. & $\begin{array}{l}\text { Para facilitar os cálculos na hora de } \\
\text { fazer construções. }\end{array}$ \\
\hline Q. 8: & $\begin{array}{l}\text { Para saber mais as origens } \\
\text { da matemática }\end{array}$ & Poder explicativo. & $\begin{array}{l}\text { Para nos aprofundarmos nas } \\
\text { origens das fórmulas. }\end{array}$ \\
\hline
\end{tabular}

Fonte: Da pesquisa

Na q. 1, no APC2, o aluno manteve a mesma opinião quanto a importância da Matemática no cotidiano. Na q. 3, acrescentou o valor da representação gráfica. No APC1, em relação as q. 6 e 7, respondeu não saber, mas após a aplicação, no APC2, justificou de uma forma que consideramos adequada com as explicações, como resolver problemas relacionados a medidas, facilitar cálculos nas construções. E continuou na q. 8 a considerar importante a história da Matemática para a compreensão das origens.

Quadro 4: Respostas do aluno

\begin{tabular}{|c|c|c|c|}
\hline Aluno 4 & APC 1 & Valores cognitivos & APC 2 \\
\hline Q. 1: & $\begin{array}{l}\text { Geralmente o básico é } \\
\text { usado, algumas coisas são } \\
\text { inutilizáveis, a } \\
\text { matemática é essencial. }\end{array}$ & Adequação empírica. & $\begin{array}{l}\text { A matemática é usada no dia-a-dia, } \\
\text { constantemente precisamos de } \\
\text { cálculos matemáticos. }\end{array}$ \\
\hline Q. 3: & Alternativas $2,3,5,6$ & Adequação empírica. & Alternativas $1,2,3,5,6,9$. \\
\hline Q. 6: & Para resolver geometria. & Poder explicativo. & Para resolver cálculos astronômicos. \\
\hline Q. 7: & $\begin{array}{l}\text { Queriam medir as } \\
\text { pirâmides. }\end{array}$ & $\begin{array}{l}\text { Poder explicativo, } \\
\text { simplicidade, } \\
\text { adequação empírica, } \\
\text { generalização. }\end{array}$ & $\begin{array}{l}\text { Para facilitar os cálculos, faziam } \\
\text { previsões para os movimentos do Sol, } \\
\text { da Lua e dos planetas. }\end{array}$ \\
\hline Q. 8: & $\begin{array}{l}\text { A matemática não se } \\
\text { baseia nos cálculos, mas } \\
\text { tem toda uma história. }\end{array}$ & Poder explicativo. & $\begin{array}{l}\text { Adquirir mais conhecimento é sempre } \\
\text { bom. }\end{array}$ \\
\hline
\end{tabular}

Fonte: Da pesquisa 
Na q. 1, o aluno considera importante a matemática, mas salienta que há conteúdos que não são úteis, já no APC 2, ele afirma que sempre usamos os cálculos matemáticos no cotidiano. Consideramos que o valor cognitivo da adequação empírica está presente após a aplicação. Acrescentou que contribuiu para resolver problemas tanto da matemática como em outras disciplinas e a importância da representação gráfica. A q. 6 e a q. 7 foram respondidas no APC 2 de forma correta com o conteúdo explicado, pois o conhecimento prévio do aluno sobre geometria foi reforçado com novas informações históricas e atividades que enfatizavam a importância de elementos da geometria para o desenvolvimento da trigonometria. Analisamos que o aluno incorporou ao seu conhecimento os valores cognitivos, pois afirmou no APC 2 que a história da matemática traz conhecimento.

\section{Análise dos resultados da aplicação}

Representamos, no quadro 5, a análise das respostas dos 23 alunos que responderam o APC 1 e o APC 2 e participaram da aplicação da sequência didática.

Quadro 5: Respostas dos 23 alunos

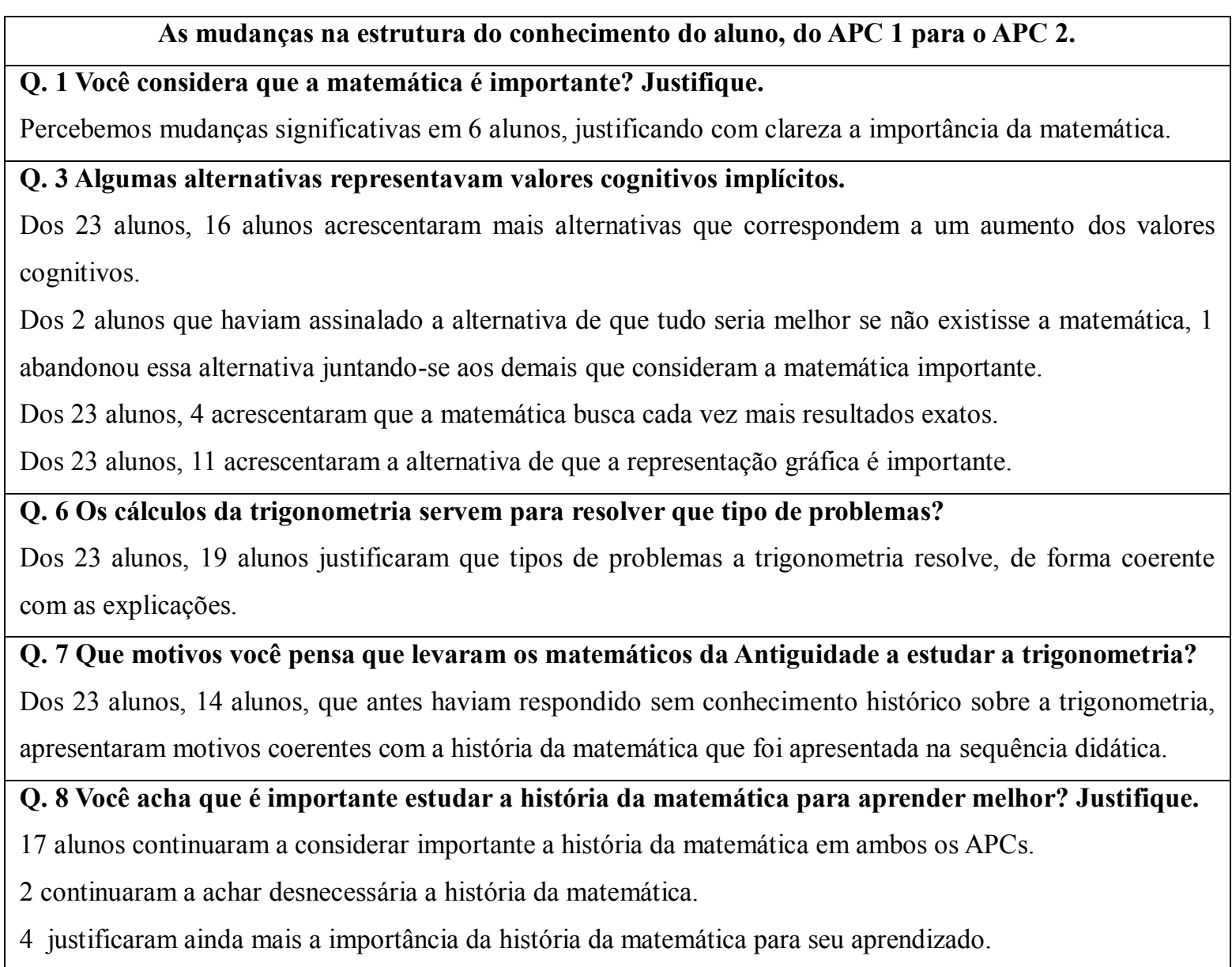

Fonte: Da pesquisa

A representação gráfica tornou-se mais importante para os alunos após a aplicação da sequência didática. Foi a alternativa em que houve mais mudanças nos APCs, com 76,67\% dos alunos.

Para 53,33\% dos alunos, a trigonometria tem a ver com os problemas reais, o que, a nosso ver, mostra que as atividades foram contextualizadas usando exemplos reais.

O fato de $53,33 \%$ dos alunos ter compreendido que o conhecimento de trigonometria foi construído por vários povos e nações trouxe-nos satisfação, pois humaniza a Matemática e também porque $46,67 \%$ dos alunos destacaram que as fórmulas da trigonometria evoluíram, apresentando mais 
clareza e simplicidade. Observamos que os alunos perceberam que a matemática não é imutável, mas que sempre poderá evoluir.

A importância da trigonometria para o desenvolvimento de outras áreas de conhecimento representou $36,67 \%$ das respostas dos alunos, evidenciando o valor cognitivo consistência na trigonometria. Destacamos que necessitaríamos de mais aulas para aplicar as funções trigonométricas para resolver problemas de outras áreas de conhecimento. Mesmo assim, dos 30 alunos que responderam o questionário, $30 \%$ deles responderam que a trigonometria explica vários fenômenos e pode ser aplicada para resolver problemas.

Nas atividades realizadas, as respostas dos alunos evidenciam que a nossa sequência didática obteve os resultados almejados na pesquisa, pois os alunos reconheceram os valores cognitivos da matemática e realizaram as atividades cuja elaboração a história da trigonometria subsidiou.

Elaboramos um esquema, sintetizando respostas de alguns alunos no APC 2 quanto à importância da história da Matemática e dos valores da Matemática para eles:

Esquema 1: Importância da história da Matemática

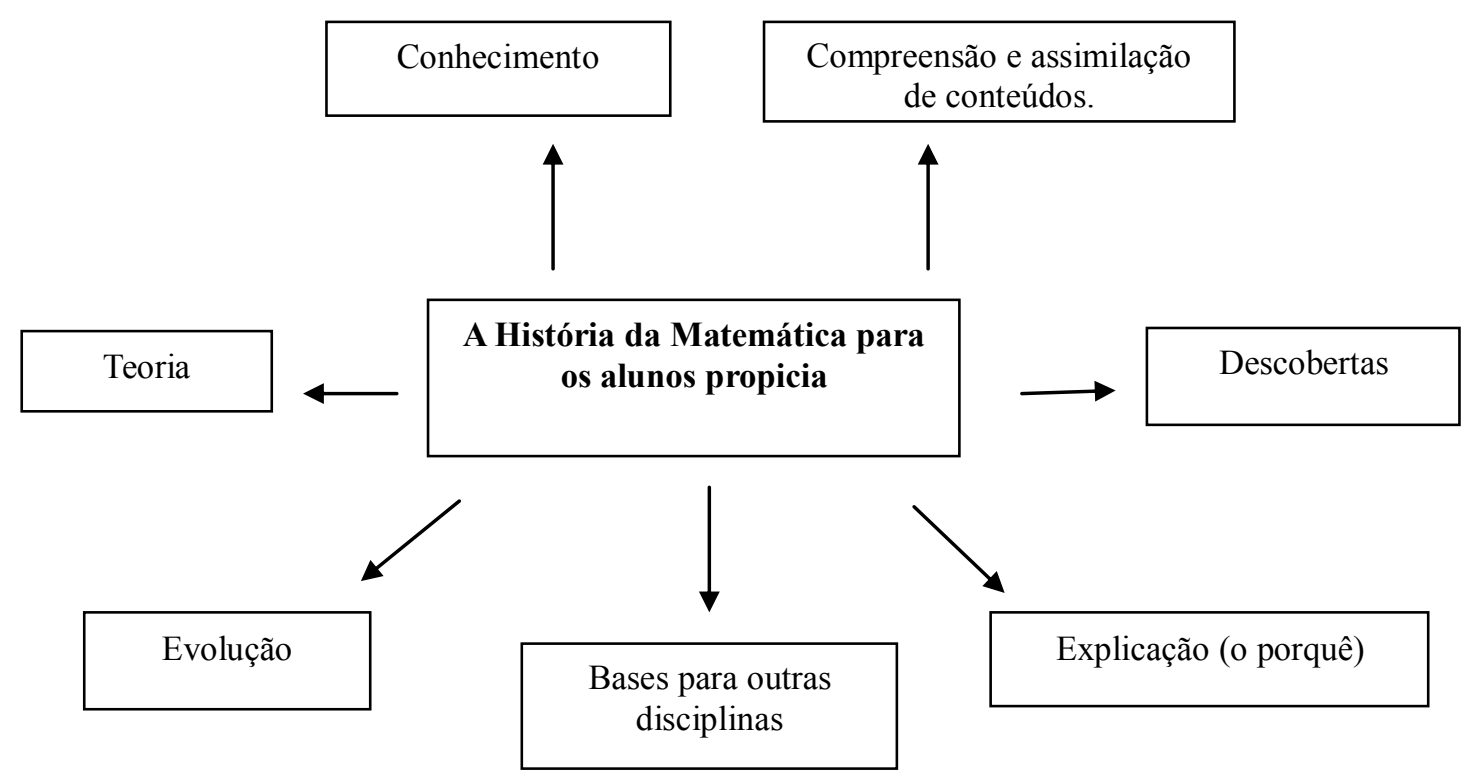

Fonte: Da pesquisa

Este esquema representa a opinião dos alunos após a aplicação da sequência didática. $\mathrm{Na}$ fundamentação teórica de nossa dissertação, citamos vários referenciais que defendem o uso da História da Matemática em sala de aula por propiciar elementos que auxiliam na aprendizagem, como podemos citar:

"a história aumenta a motivação para a aprendizagem; articula a Matemática com outras ciências" (SAD, 2004, p. 4)

"facilita o processo investigatório do conhecimento matemático em sala de aula" (MENDES, 1997, p. 15)

"como um fio condutor de raciocínios" (BATISTA, 2005, p. 736)

Assim, o esquema anterior apresenta argumentos dos alunos que são semelhantes aos de alguns autores. Quando analisamos as respostas dos alunos, observamos que foi por meio da sequência didática aplicada na aula que eles compreenderam a importância da História da Matemática para a trigonometria.

No APC 2, foi feita a seguinte pergunta aos alunos: "Para você a matemática possui um valor que a torna importante nos estudos? Justifique." Destacamos algumas respostas dos 
alunos que explicitam alguns dos valores cognitivos da matemática, como poder explicativo, exatidão, simplicidade, consistência e adequação empírica. $\mathrm{O}$ esquema ilustra a manifestação dos valores cognitivos da matemática na escrita dos alunos e uma mudança quanto às suas concepções do APC 1 para o APC 2. Analisamos que no APC 2, muitos alunos justificaram suas respostas, com conhecimento, com exemplos da história da trigonometria, conforme ilustramos no esquema abaixo.

Esquema 2: Valores cognitivos manifestados

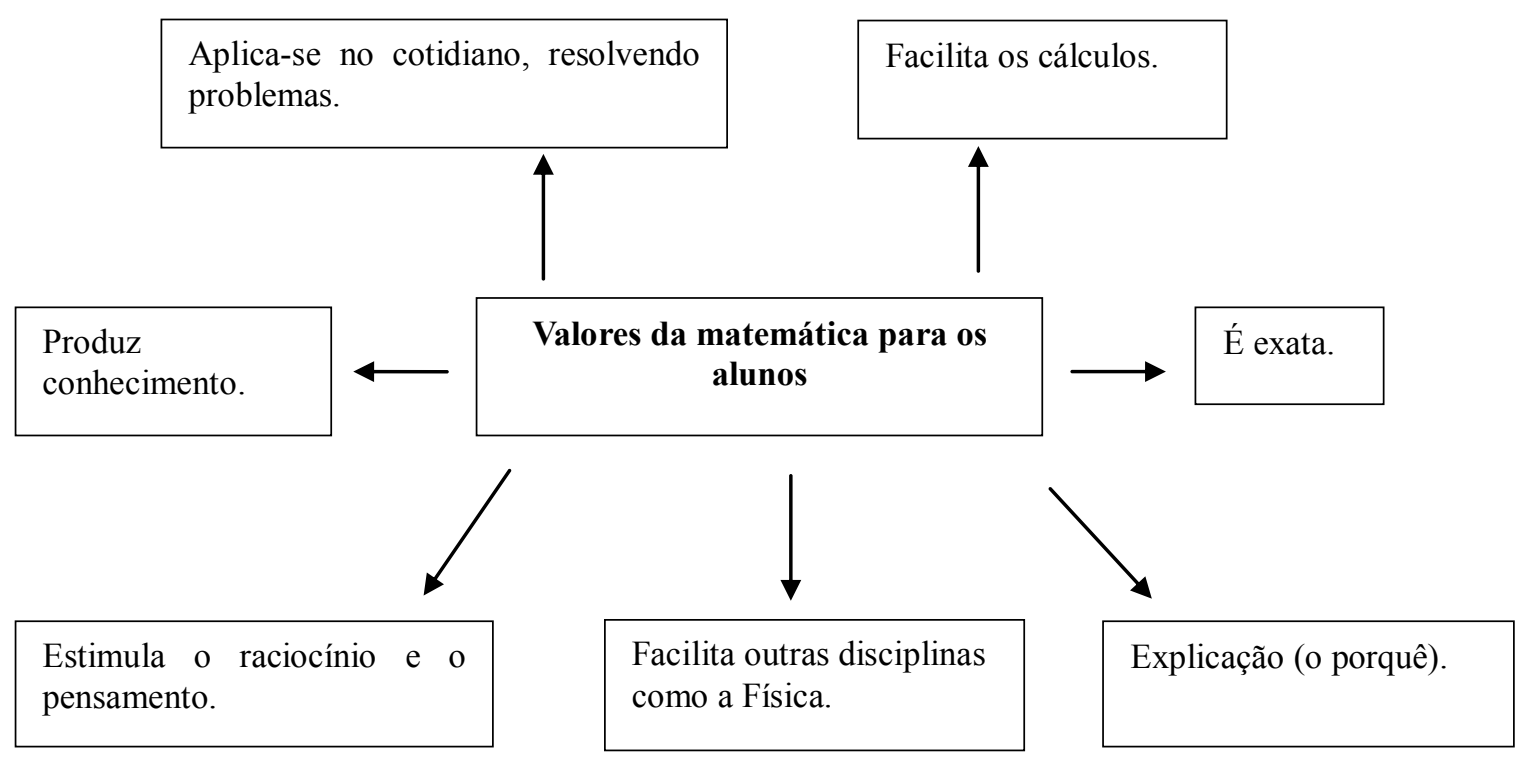

Fonte: Da pesquisa

Em nossa análise, consideramos que o fato de o aluno explicitar os valores da matemática significa que houve uma incorporação destes no seu conhecimento, os mesmos valores cognitivos que foram manifestados e evidenciados em nossa sequência didática, numa abordagem histórico-filosófica da trigonometria.

\section{Considerações Finais}

As adequações e transformações necessárias para a construção da abordagem históricofilosófica ocorreram por meio de diversos referenciais que, articulados, contribuíram para os resultados da investigação. Para alcançar uma aprendizagem escolar mais significativa em nossos alunos, foi necessário investigar um instrumento que auxiliasse na elaboração e na avaliação de uma sequência didática propiciadora deste tipo de aprendizagem.

Com o instrumento APC, da Aprendizagem Significativa, podemos inferir que, analisando o desenvolvimento dos alunos durante a experimentação e dos resultados apresentados, ele contribui para o ensino e aprendizagem de trigonometria, auxiliando na concepção, na realização e nas análises da sequência didática. Por meio da comparação entre os questionários aplicados antes e depois da sequência didática, validamos os resultados da investigação. Nas atividades realizadas, as respostas dos alunos evidenciam que a nossa sequência didática obteve os resultados almejados na pesquisa, pois os alunos reconheceram os valores cognitivos da Matemática e realizaram as atividades cuja elaboração a história da trigonometria subsidiou.

Verificamos, por meio dos APCs, que novas informações foram ancoradas nas proposições preexistentes na estrutura cognitiva do indivíduo, ocorrendo a aprendizagem de trigonometria. Assim, acreditamos que nossas hipóteses de pesquisa foram validadas e o referencial da Aprendizagem 
Significativa que fundamentou esta pesquisa permitiu a consolidação de uma abordagem históricofilosófica na Educação Matemática.

\section{Referências}

ARTIGUE, Michèle. Engenharia Didática. In: Didática das Matemáticas, BRUN, J. (org). Lisboa: Instituto Piaget, p. 193-217, 1996.

BATISTA, Irinéa de L. Einstein e as interfaces entre história, filosofia e ensino de física. Scientiae Studia, São Paulo, v. 3, n. 4, p. 733-9, 2005.

LACEY, Hugh. Valores e atividade científica. São Paulo, Discurso Editorial, 1998.

MENDES, Iran Abreu. Ensino de Trigonometria através de atividades históricas. Rio Grande do Norte, 1997. 165 f. Dissertação (Mestrado em Educação) - Universidade Federal do Rio Grande do Norte.

MIGUEL, Antonio. Três estudos sobre história e educação Matemática. Tese de Doutoramento, Faculdade de Educação, Universidade Estadual de Campinas, 1993.

MIGUEL, Antonio. Contribuição crítica à discussão acerca da participação da história e da epistemologia da Matemática na investigação em educação Matemática. Horizontes, Bragança Paulista, v. 22, n. 1, p. 71-107, jan./jun. 2004.

NOVAK, Joseph D.; GOWIN, Bob D. Aprender a aprender. 2.ed. Lisboa: Plátano Edições técnicas, 1999.

PAIS, Luiz Carlos. Didática da Matemática: uma análise da influência francesa. Belo Horizonte: Autêntica, 2002.

SAD, Lígia A. Educação Matemática: unidade na história e nos objetivos educacionais. In: VII EPEM. Anais..., São Paulo - SP: junho de 2004, p. 1-5. 